Author Accepted Manuscript

Selecting hotel staff: why best practice doesn't always work

\title{
Cliff Lockyer
}

Fraser of Allander Institute, University of Strathclyde

Dora Scholarios

Department of Human Resource Management, University of Strathclyde

4716 words 
Cliff Lockyer

Research Fellow

Fraser of Allander Institute

University of Strathclyde

100 Cathedral Street

Glasgow G4 0LN

Tel: 0141-548-3198

Fax: 0141-552-8347

e-mail: c.j.lockyer@strath.ac.uk

Dora Scholarios

Reader

Department of Human Resource Management

University of Strathclyde

50 Richmond Street

Glasgow G1 1XT

Tel: 0141-548-3135

Fax: 0141-552-3581

e-mail: d.scholarios@strath.ac.uk 


\begin{abstract}
$\underline{\text { Abstract }}$
This paper considers the nature of 'best practice' recruitment and selection in the hotel sector. Data from a sample of Scottish hotels indicates a reliance on informal methods, particularly in smaller hotels. In larger and chain hotels, structured procedures, including references, application forms and panel interviews, are evident, but here too, these methods seem inadequate for dealing with recruitment and quality problems especially in meeting temporary staffing needs. Case study evidence contrasts two alternative strategies: a successful holistic strategy based on management of social processes important for selection, and a more conventional bureaucratic strategy. Each strategy depends on a complex interrelationship between business and labour market considerations, the ownership and management structure of the hotel, and the tenure and experience of those responsible for selection. This evidence indicates that, for the hotel industry, the holistic strategy is an alternative to conventional notions of 'best practice' recommended in the HRM literature.
\end{abstract}

\title{
$\underline{\text { Keywords }}$
}

Hotels, Recruitment, Selection, Best practice, Social process 


\section{INTRODUCTION}

The effectiveness of service organisations is often linked with the individual qualities of their employees (Goldsmith, Nickson, Sloan, \& Wood, 1997; Schneider and Bowen, 1995). Mahesh (1988) proposed “the customer's perception of service quality is more directly linked to the morale, motivation, knowledge, skills and authority of front line staff who are in direct contact with customers, than in the case of a product selling organisation"(p. 10). In the hotel industry, however, there is little evidence of systematic selection practice to identify quality service characteristics. Some evidence exists for the systematic use of structured interviews and biographical data in larger and chain hotels (Ineson \& Brown, 1992; Law \& Wong, 1997), but practice generally is acknowledged to be informal and basic, particularly for non-managerial staff (Kelliher \& Johnson, 1987; Waryszak \& Bauer, 1993).

The selection literature recommends the development of job and person specifications and the use of reliable and valid methods based on detailed job analysis, even for small businesses (Hunter \& Schmidt, 1982). Yet this conventional notion of 'best practice' in selection may be problematic in the hotel industry which has typically high levels of staff turnover and hence immediate and shifting needs in its search for staff.

The empirical evidence presented here demonstrates differences in recruitment contexts and practice across hotels of different size and type. Across all hotels there is a reliance on informal methods with no proven connection with the candidate qualities identified as desirable. Analysis of the methods that selectors' value suggests that selection strategy may be linked to other factors which directly shape practice. The study identifies case examples with different ownership and management structures and shows how contextual factors impact the adoption of idealised models of selection, especially the role played by the hotel manager, proprietor or member of personnel involved in the selection process. The alternative strategies identified suggest a possible framework for 'best practice' 
in hotels based on the interplay between the external environment, organisation structure, and the selector.

\section{BARRIERS TO 'BEST PRACTICE' IN THE HOTEL INDUSTRY}

Advances in selection for customer facing service jobs lie mostly in the area of personality testing (McDaniel \& Frei, 1998; Mount, Barrick, \& Stewart, 1998). Hogan, Hogan and Busch's (1984) construct of "service orientation" identifies several personality characteristics useful for service work, such as courtesy, consideration, tact, perceptiveness, and good communication skills, qualities which are also thought to be critical in the hospitality industry (Kitching 1994). There is little evidence, however, of any systematic attempt to assess these in selecting front-line staff, particularly in the form of psychometric personality tests where most of the research effort has been directed (Berger \& Ghei, 1995; IDS, 2003). Surveys of practice in different sectors, occupations and countries consistently reveal that the most commonly used methods have low reliability and validity for predicting future job performance (e.g., Dany \& Torchy, 1994; DeMilia, Smith \& Brown, 1994; IDS, 2003; IRS, 1997; Keenan, 1995; Marsden, 1994; Rowe, Williams, \& Day, 1994). Service sector employers rely on unstructured application forms and interviews often conducted by untrained interviewers (Poppleton, 1989) and the general consensus is that selection in the hotel industry tends to be informal, simplistic, and reactive (Kelliher \& Johnston, 1987; Croney, 1988; Price, 1994).

HRM literature suggests four reasons for the ineffectiveness of 'idealised' models of practice. Firstly, idealised models fail to consider the constraints external factors place on recruitment and selection. Conventionally, hotel staffing problems are explained in terms of long and unsocial hours (Mullins, 1995); the unpredictable and often seasonal demand against high fixed costs; low pay; casualisation; high turnover; and poor personnel professionalism (Croney, 1988; HCTC, 1994; Kelliher \& Johnson, 1987; Price, 1994; 
Roberts, 1995; Rowley \& Richardson, 2000; Wood, 1997). These problems have been found to be more acute for hotels relative to other industries (Rowley, et al., 2000).

Secondly, variation in hotel size, location, and ownership makes the prescription of a 'best practice' selection model problematic (Medlik, 1989). Some $80 \%$ of hotels in the UK employ fewer than 50 staff (Annual Business Inquiry, 2000) and organisational size has been linked, more generally, to having the resources to employ sophisticated methods (Lee-Ross, 1998; Millward, et al., 1992; Nolan, 2002). The use of multiple selection procedures or hurdles increases in larger or chain hotels which are generally more likely to have specialised personnel functions concerned with the formalisation and standardisation of selection (Olian \& Rynes, 1984).

Thirdly, differences between individualised versus standardised service have also been linked to different HRM approaches and practices required to maintain effective functioning (Lashley, 1998; Schmenner, 1995). HR practice in mass service organisations, with a limited amount of customisation is typically characterised by predictability, the existence of routine tasks, and role specific power, such as that held by personnel managers. In contrast, 'professional service' organizations are characterised by a high level of customisation to customer needs, with HR practice shaped by low predictability, low volume, and the allocation of power in shaping objectives to key individuals.

Finally, the functionalised nature of HRM and selection processes in chain hotels also implies that managers and personnel staff in these hotels will play a different role in the selection decision making from management in independent hotels (Nankeris \& Debrah, 1996). There has been little attention, however, devoted to the role played by selectors' knowledge of the local labour market. Importantly, MacHatton, VanDyke, and Steiner (1997) suggested that the more sophisticated selection techniques used by chain restaurants compared to locally-owned restaurants could be explained by the fact that large companies' 
managers were 'outsiders' in the local community, and, in contrast, independent owners could make more effective use of the 'grapevine'. A related point was the relatively higher level of turnover of managers in chains. Selection decision makers who hold short tenure in their hotel may not have the same degree of knowledge, experience, contacts and influence within the hotel or the local community to understand the local labour market and make use of informal networks.

This combination of diversity and context leads to three propositions regarding recruitment and selection in the hotel industry which are examined in this study.

1. Hotel recruitment context, labour market constraints and selection decision makers vary according to size and ownership/management structures.

2. Recruitment and selection practice in all hotels is based largely on non-validated and informal practices, although larger hotels will adopt a more structured approach.

3. 'Best practice' is not necessarily represented by the more structured approach adopted in larger hotels; rather it is determined by the interaction of internal and external context, especially the labour market, the nature of the service/product, the ownership/management structure of the hotel, and the selector.

\section{METHODOLOGY}

Survey of Scottish Hotels

The first two propositions were examined in a survey of current practice and recruitment conditions in Scottish hotels. The sample was drawn from a representative database (Lockyer, Malloy \& LeTissier, 1998). This was proportionately stratified by size, location (city, country, suburban) and type (independent or chain), but skewed towards hotels with more than10 rooms as it was felt that smaller hotels would have little recruitment activity. The postal questionnaire elicited 81 returns, a response rate of $27 \%$. 
Table I provides a breakdown of the key characteristics of the respondents. These were split almost evenly between independent hotels and those which were part of a hotel group. The majority of hotels that were part of a chain tended to have more than 25 employees, whilst 'independents' were evenly split across the two sizebands. Most small hotels tended to be independent rural hotels. Larger hotels were more evenly split across the three location categories.

\section{take in Table I}

The questionnaire gathered information on: (a) context factors, including labour market issues (e.g., labour supply and cost), organisation (e.g., size, ownership) and selector characteristics (e.g., tenure, experience), and (b) the methods of recruitment and selection used for recently hired front-line employees. Eleven of the most common recruitment methods were listed and respondents asked to indicate which were used. For a range of selection methods, respondents were asked to provide ratings on a 5-point scale for both the frequency of use and the perceived value of the method. Data relating to (a) was obtained for all survey respondents $(\mathrm{N}=81)$; however, because respondents were asked to consider a recent appointment in a job area of choice in their answers for (b), only data for a subsample $(\mathrm{N}=54)$ was available for front-line service staff.

\section{Interviews with Selectors}

The third proposition was explored through interviews with owners, managers or personnel officers primarily responsible for selection in nine hotels (each employing more than 50 staff) who had responded to the survey. The hotels represented distinct recruitment contexts: chain city hotels (2), countryside chains (2), countryside independents (2), suburban chains (2), and suburban independents (1). The interviews probed the areas addressed in the survey focusing on the rationale behind different recruitment and selection methods used and the perceived usefulness of a particular method for identifying specific candidate qualities. 


\section{$\underline{\text { RESULTS }}$}

Proposition 1 can be considered by examining Table I, which illustrates differences across hotel size and type in recruitment activity, the effects of external context, and the role of the selector(s). In all hotels, most recruitment activity was for replacement purposes, with only a small number of small and large hotels reporting the creation of new posts. Not surprisingly, larger hotels and chains tended to receive a greater number of unsolicited applications per month as well as applications for specific vacancies, but the majority of recruitment activity in these hotels was directed towards temporary staff.

Eighty-five per cent of the total sample reported experiencing a shortage of suitable applicants, with larger hotels affected slightly more. Larger and chain hotels also were more likely to report being affected by increasing staff costs, labour turnover and legislation (possibly reflecting the influence of a specialised personnel function implementing legislation compliant policies in hotels which are part of chains). Price competition affected a greater proportion of small hotels.

The sample was evenly split in terms of the person responsible for recruitment and selection activity. The presence of personnel staff or a personnel department was directly related to the size of the hotel. Forty-one percent of larger hotels reported having at least one personnel person compared to only $7 \%$ of smaller hotels. Larger hotels were also twice as likely to split the responsibility for recruitment and selection between several members of staff. Smaller establishments, on the other hand, were more likely to allocate this responsibility to one person only, usually the general manager or the hotel proprietor, while chains were most likely to allocate the responsibility to HR. Selectors in smaller hotels also reported longer tenure than selectors in larger hotels or chains. Three quarters of the selectors reported only work-based experience of recruitment and selection; about half had attended 
short courses related to selection (e.g., in-house interview training) and only one third had any personnel-related qualifications. A greater proportion of respondents in the larger and chain hotels had undergone training of some kind related to selection.

Thus, consistent with Proposition 1, the recruitment context of large and chain hotels differed from that of small and independent hotels. The former experienced both greater recruitment activity and greater recruitment difficulties and skill shortages. They also were more likely to formalise processes through an HR department or officer.

Proposition 2, regarding actual practice used to recruit and select front-line staff in hotels, was examined using a subset $(\mathrm{N}=54)$ of the total sample of respondents. The most frequently cited method of recruiting was referrals from existing staff; this was mentioned by three quarters of respondents (see Table II). Advertisements in the local press, government agencies, unsolicited correspondence, educational institutions and past employees were other popular methods cited. The number of recruitment methods adopted by hotels increased relative to the number of staff employed. Government agencies, local press and educational institutions were more likely to be used by larger hotels whilst smaller hotels were more likely to rely on informal methods such as past employees.

\section{take in Table II}

With regard to selection methods, the interview was the most commonly used method and, as expected, there was a general preference in all hotels for the less technically valid methods such as references and application forms (see Table III). Informal methods, such as personal recommendations, telephone conversations and personal knowledge of the applicant were also frequently used. Very few hotels reported using formalised assessment methods such as psychometric tests, job/work samples or assessment centers.

Interestingly not all the frequently used methods were highly valued and regarded by selectors as providing successful future employees. In Table III, this is indicated by 
subtracting each respondent's frequency rating from their value rating for each method. Negative results imply that respondents placed low value on a frequently used method, such as the application form, but placed high value on an infrequently used method, such as psychometric tests.

The importance of information gained informally, such as personal knowledge of the applicant was rated high relative to use, suggesting that such sources of information, whilst considered useful, are not always available. The high overall value attached to more systematic methods relative to use, such as ability or personality testing and work samples, suggest respondents were aware of the potential of such methods as useful assessment tools although very few organizations attempted to use them.

Small hotels were more likely to use informal methods such as personal recommendations and telephone conversations over written applications. This may reflect the lower levels of recruitment experienced by these hotels or the lack of formal training of selectors. Larger hotels, on the other hand, appeared to adopt more formalised procedures, making more use of application forms and CVs. This is not surprising, given the high volume of recruitment activity experienced by these hotels and the existence of selection policies established by head office. It is likely that many chains will view the use of standard application forms as one way of trying to ensure consistency in the quality of their staff across hotels. Equally, application forms are a means to elicit information such as home address, national insurance details and references, allowing for almost immediate employment of the applicant and minimising the time spent on processing such information. This is particularly important given the high proportion of hotels where responsibility for personnel was only one of many functions performed by the general manager or proprietor. This supports the finding that the application form was the only method perceived as being of less value than its actual use reflected. Thus, selectors may not necessarily perceive the 
application form as a useful tool to identify the 'right' candidates, but make use of application forms to obtain the information necessary for an employment contract to be issued.

Larger hotels also placed higher value on more structured assessment methods such as testing, work samples and references compared to small hotels, possibly reflecting the higher number of selectors in large hotels who had been trained in personnel-related issues. Informal methods were used less frequently but were still rated as valuable, suggesting that selectors in larger hotels, perhaps as a result of their shorter tenure, may not always be able to draw on such networks. Lastly, larger hotels tended to place more value on interviews with at least two interviewers compared to smaller hotels, reflecting the involvement of department supervisors or managers in the interview process.

\section{take in Table III}

Considering Propositions 1 and 2 overall, then, the survey results suggest two distinct profiles of recruitment and selection practice representing small/independent versus larger/chain hotels. Larger and chain hotels are more likely to have a dedicated personnel function or employee to administer and sometimes participate in the selection process, and staff are more likely to have a formal personnel qualification. Responsibility for recruitment and selection in small hotels and independents tends to lie with either the general manager or the owner who often have little formal personnel training. In general, larger/chain hotels reflect the conventional notion of 'best practice', based on systematized processes and more frequent use of valid practices, found in the HRM literature. Yet, they also seem to report more recruitment difficulties than smaller hotels.

Proposition 3 attempts to provide an explanation for why the recommended 'best practice' approach may not always result in optimal selection. Using qualitative data to examine this proposition, we can illustrate the approach to successful selection adopted by smaller and independent hotels where formal HR qualifications and systems are absent or 
tailored to the hotel's needs. Selectors in smaller hotels and independents often build an informal profile of their labour market supply, marketplace, desirable candidate qualities and relevant selection information through continuous attention to external relations (e.g., with the local population) and their own changing requirements. Much of this activity often hinges on the input of key individuals, such as the owner or manager, and takes the approach of matching individuals to organisational culture rather than specific job requirements and experience of the labour market rather than reliance on best selection techniques. Even chain hotels with a customized service process also tend to reflect this approach. In contrast, larger hotels, offering a standard service, tend to adopt a more functionalised view of personnel procedures, emphasizing systematisation of selection practice, through references, application forms, or panel interviews, and maintaining an impersonal application of human resource practices.

Of our nine case study hotels, the three independent hotels and the customized luxury chain hotel exemplify this 'holistic' strategy. The five chain hotels, whether in city, country or suburban locations, conformed to centralized procedures regardless of local labour market and recruitment difficulties. Although all hotels experienced the skill shortages, high turnover, and recruitment difficulties inherent to the hotel industry, the more holistic strategies appeared to present a more effective model for 'best practice'. Two of the case study hotels are used here to illustrate these contrasts.

\section{The Holistic Strategy in the Luxury Country Hotel}

The management team in the luxury countryside hotel (part of a UK-wide group) emphasised the need to provide a high quality of service and this was filtered through all levels of the hotel's organisational strategy. The personnel manager emphasised, "the team are aware they are developing a product....the hotel structure is formed by reacting to the customers". The high importance attached to the personnel function was formally recognised 
by having the personnel manager on the senior management team. Whilst part of a group with a centralised personnel policy, the hotel had considerable autonomy in the conduct of its recruitment and selection practice. "Employee qualities have to reflect the needs of this hotel, rather than the needs of the group". Following initial screening by personnel, heads of department did most of the interviewing and were responsible for selection decisions for staff in their departments. All department heads had received training in selection techniques.

The personnel manager combined both a postgraduate personnel qualification with wide experience of hotel operations. Drawing on previous experience, she recognised the importance of the local community as the main source of staff, and hence the need to ensure the hotel was perceived as a good employer. In the selection process, considerable emphasis was placed on the expectations the candidate brought to the job. For example, younger staff with no experience were often given work trials to provide them with a realistic preview of the job. Exit interviews were also regularly conducted to identify sources of staff dissatisfaction or hotel-employee mismatches. Other recruitment strategies used included visiting local schools and introducing the hotel industry as a possible career for school leavers. These strategies had resulted in an over supply of candidates for service positions, making the screening and interview process very important to sustain the quality of service for customers. As the personnel manager adamantly stated, "we don't want to hire arms and legs".

The selection strategy here reflected a holistic approach, integrating the organisation's pursuit of quality, as operationalised by the personnel manager, management team, and heads of department, and an approach which "cultivated" the local labour market. The selection process was described as “not very scientific - you couldn’t apply the textbook to reality"; however, there was a clear coherence to the pursuit of quality through the selection process. 


\section{The Bureaucratised Strategy in the City Chain Hotel}

This city centre hotel was part of a large chain catering mainly for functions and the business trade. A series of reorganisations of the company had led to several changes in personnel staffing and policy in recent years. A further programme of change involving a delayering of the management structure was imminent.

Following the restructuring, the HR administrator was appointed to oversee staffing for three hotels in the chain. She was not from the local area, and, despite holding a personnel-related qualification, had only recently moved into personnel, after spending two years working in the sales division of the company. Working between the three hotels posed problems in developing an understanding of either the customer or local labour markets of the three hotels. The HR administrator recognised differences in the 'cultures' of the three hotels and how this might impact person 'fit', but lacked the means to influence selection to reflect such differences. Thus, the recruitment procedure reflected more formal recruitment methods such as internal advertising, newspaper ads and placing ads in local colleges or universities rather than informal sources.

The reduction in the personnel function through the recent restructuring programme had resulted in selection being devolved to heads of department, with the role of the personnel manager described as a "policing role". Devolved responsibility was expected to allow department heads, often with little experience of selection, to create the style of their own department. On the other hand, the HR administrator policed the process by promoting a 'back to basics' approach to training covering good interview techniques and legal requirements and by emphasising structured and formalised selection procedures devised by head office and training (e.g., application forms).

The restructuring had led to some confusion as to what kinds of qualities were expected of new staff. Clashes were evident between the informality in selection adopted by 
chefs to maintain what they regarded as essential standards versus the need for formality and consistency with company policy. Additionally, heads of department often had to confront a clash between the need to restrict staff numbers and costs with flexibility in staff numbers to meet varying levels of activity. This led to informality in selection methods, and job offers being made by heads of departments without following the required procedures.

In this second example, the contextual factors combined to structure the selection procedure into a less adequate form, and as a consequence the hotel suffered from recruitment difficulties and high levels of turnover (approx $40 \%$ per annum). Frequent structural changes and the adoption of a devolved selection procedure without adequate training had resulted in a preoccupation by personnel with following procedures and meeting legal requirements.

\section{CONCLUSIONS}

Our survey confirms the general lack of systematic selection procedures for the hotel sector, particularly in smaller hotels. The data also revealed, however, that large and chain hotels, notwithstanding more sophisticated personnel resources, were finding difficulty meeting the demands imposed by labour market and recruitment constraints. The study suggests an alternative approach to 'best practice' which is based less on the development of reliable, valid techniques and more on attention to the social processes of selection.

The two case examples illustrated the interaction of environmental, organisational and selector characteristics with recruitment and selection procedures for each of the hotels where interviews were conducted. In the first example, an agreed focus on quality led to positive interaction between the three layers of context, whilst in the second, the forces in the differing layers appeared to act against one another to weaken and fragment the recruitment and selection procedure. In a strategy also shown in the other independent hotels, the chain country hotel reflected a 'holistic' approach typified by a high awareness of customer 
expectations, local labour market characteristics, and the types of employees which could represent the culture of service and customer base to which they aspired. Integral to this was a personnel manager whose potential influence is shown in two ways: first, in terms of their knowledge of the hotel industry and general awareness of the environmental context of the individual hotel; and secondly, in terms of their status within the hotel and the importance placed on selection within the hotel structure.

By contrast, the city centre chain hotel, as with the other chain hotels in our case studies, operated a functionalised, more bureaucratic model of recruitment and selection, with significantly more problems in solving recruitment difficulties and, in general, managing the constraints imposed by their environment and internal organisational changes. This bureaucratised approach, while it reflects the greater use of 'sophisticated' reliable methods, may not allow the necessary adaptation to the hotel industry's changing recruitment environment.

This illustrates the role of context in shaping 'best' selection practice and in particular the dynamic nature of the recruitment and selection process, often referred to as a social process approach to selection (e.g., Herriot, 1989; Iles \& Salaman, 1995). In contrast to the traditional approach of technical validity, this holds that successful selection can be achieved by methods which the selection literature typically regards as unsophisticated and unreliable, including personal recommendations and interviews, and has been shown to be particularly relevant for small businesses and some recruitment contexts (e.g., Scholarios \& Lockyer, 1999). Lack of formalisation can be compensated by the effective use of local networks which are often not accessible by transient managers or HR officers in the chain hotels. The success of this less formal approach, however, depends on effective local management processes which take account of contextual constraints. More specifically, 
- selectors should have knowledge of the local labour market and be able to make use of informal networks;

- attention should be paid to the internal management structure of the hotel, ensuring that there is integration between heads of department, particularly with respect to overall HRM strategy and how this shapes selection decisions;

- and individual hotels, even in larger hotel groups, would benefit from the presence of a 'champion' who can tailor appropriate selection strategy to the constraints of that hotel's environment; a 'one-size-fits all' approach appears counterproductive.

These recommendations highlight the role of the selector or 'champion' of the selection strategy and have implications for human resource issues such as manager retention, management of the employment relationship, and the training and development of selectors. The problem of high manager turnover in hotels (see for example Stalcup \& Pearson, 2001) poses a problem for such an approach where retention of managers or HR practitioners with tacit knowledge of a hotel's local labour market or customer base is central to the development of appropriate selection strategies. While some regard hotel manager mobility as enhancing skills, adaptability and career potential (Baum, 1995) there is clearly a trade-off for hotel employers in terms of replacing local knowledge and how this feeds the quality of human resource development in hotels.

In short, 'best practice' in hotel employee selection is not necessarily confined to larger/chain hotels which invest more in HRM systems. Rather, successful recruitment and selection in hotels, as in other fluid and constrained organizational environments, can be defined more in terms of management of the social context of selection rather than the technical validity of the methods used. 


\section{REFERENCES}

Baum, T. (1995) Managing Human Resources in the European Tourism and Hospitality Industry: A Strategic Approach, Chapman and Hall, London.

Berger, F. \& Ghei, A. (1995) "Employment Tests: A Facet of Hospitality Hiring”, Cornell Hotel and Restaurant Administration Quarterly, Vol 36 No 6, pp.28-35.

Croney, P. (1988) An Analysis of Human Resource Management in the UK Hotel Industry, Proceedings of The International Association of Hotel Management Schools Symposium, Leeds Polytechnic.

Dany, F., \& Torchy, V. (1994). "Recruitment and selection in Europe: Policies, practices and methods", in Brewster, C. \& Hegewisch, A. (Ed.), Policy and Practice in European Human Resource Management: The Price Waterhouse Cranfield Survey, Routledge, London and New York, pp. 68-88.

Goldsmith, A., Nickson, D., Sloan, D. \& Wood, R. C. (1997) Human Resource Management for Hospitality Services, International Thomson Business Press.

Herriot, P. (1989) (Ed.) Assessment and Selection in Organisations: Methods and Practice for Rrecruitment and Appraisal, Wiley, Chichester.

Hogan, R. T., Hogan, J. \& Busch, A. (1984) "How to measure service orientation", Journal of Applied Psychology, Vol 69 No 1, pp.167-173.

Hotel and Catering Training Company (1994) Catering and Hospitality Industry - Key Facts and Figures, HCTC, London.

Hunter \& Schmidt (1982) "Fitting people to jobs: The impact of personnel selection on national productivity", in Dunnette, M.D.\& Fleishman, E.A. (Eds.), Human Performance and Productivity: Human Capability Assessment Vol. 1., Lawrence Earlbaum, Hillsdale, NJ.

IDS (2003) Recruitment practices, Study 751.

Iles, P. \& Salaman, G. (1995), "Recruitment, selection and assessment", in Storey, J (Ed.), Human Resource Management. A Critical Text, Routledge, London, pp. 203-233.

Ineson, E.M. \& Brown, S.H.P. (1992) "The use of biodata for hotel employee selection", International Journal of Contemporary Hospitality Management, Vol 4 No 2.

IRS Employment Review. (1997), "The state of selection: an IRS survey", Employee Development Bulletin, 623, pp.8-18.

Keenan, T. (1995) "Graduate recruitment in Britain: a survey of selection methods used by organizations”, Journal of Organizational Behaviour, Vol 16, pp.303-317.

Kelliher, C. \& Johnson, K. (1987) "Personnel management in hotels - some empirical observations", International Journal of Hospitality Management, Vol 6 No 2, pp.103-108. 
Kitching, J. (1994) "Employers' work-force construction policies in the small service sector enterprise", in Atkinson J. and Storey D. (Eds.), Employment, the Small Firm and the Labour Market, Routledge, London.

Lashley, C. (1998), "Matching the management of human resources to service operations", International Journal of Contemporary Hospitality Management, Vol 10 No 1, pp.24-33.

Law \& Wong (1997) "Evaluating the effectiveness of interviews as a selection method, Australian Journal of Hospitality Management, Vol 4 No 1, pp.27-32.

Lee-Ross, D. (1998) “Australia and the small to medium-sized hotel sector", International Journal of Contemporary Hospitality Management, Vol 10, No 5, pp. 177-179.

Lockyer, CJ, Malloy, E., \& LeTissier, S. (1998). Scottish Tourist Board Business Survey: quarter 41997 and quarter 1 1998. Fraser of Allander Institute, University of Strathclyde.

MacHatton, M.T., VanDyke, T., \& Steiner, R. (1997) "Selection and retention of managers in the US restaurant sector", International Journal of Contemporary Hospitality Management, Vol 9 No 4, pp. 155-160.

Mahesh, V. S. (1988) "Effective human resource management: key to excellence in service organizations", Vikalpa, Vol 13 No 4, pp.9-15.

Marsden, P. V. (1994), "Selection methods in US establishments", Acta Sociologica, Vol 37 No 3, pp.287-310.

McDaniel, M. A. \& Frei, R L. (1998) "Validity of customer service measures in personnel selection: A review of criterion and construct evidence", Human Performance, Vol 11 No 1, pp.1-27.

Mount, M. K., Barrick, M. R. \& Stewart, G. L. (1998) "Personality predictors of performance in jobs involving interaction with others", Human Performance, Vol 11, pp.145-166.

Medlik, S. (1989) The Business of Hotels, Heinemann, $2^{\text {nd }}$ edition.

Millward, N., Stevens, M. , Smart, D., \& Hawes, W. R. (1992) Workplace Industrial Relations in Transition. Aldershot, Dartmouth, Hants..

Mullins, L. J. (1995) Hospitality Management: A Human Resources Approach, Pitman Publishing, London, $2^{\text {nd }}$ edition.

Nankeris, A. R. \& Debrah, Y. (1996) "Human resource management in hotels: A comparative study”, Tourism Management, Vol 16 No7, pp.507-513.

Nolan, C. (2002) "Human resource development in the Irish hotel industry: the case of the small firm”, Journal of European Industrial Training, Vol 26 No 2. 
Olian, J.D. \& Rynes, S.L. (1984) "Organizational staffing. Integrating practice with strategy", Industrial Relations, Vol 23 No 2, pp.170-183.

Poppleton, S. (1989) "Service occupations", in Herriot, P. (Ed.), Assessment and Selection in Organizations: Methods and Practice for Recruitment and Appraisal, Wiley, London.

Price, L. (1994) "Poor personnel practice in the hotel and catering industry: does it matter?" Human Resource Management Journal, Vol 4 No 4, pp.44-62.

Roberts, J. (1995) Human Resource Practice in the Hospitality Industry, Hodder and Stoughton, London.

Rowe, P. M., Williams, M. C., \& Day, A. L. (1994), "Selection procedures in North America", International Journal of Selection and Assessment, Vol 2 No 4, pp.74-79.

Rowley, G. and Richardson, M. (2000), "Work, employment and flexibility in hospitality", in K. Purcell (Ed.), Changing Boundaries in Employment, Bristol Academic Press, Bristol.

Rowley, G., Purcell, K., Richardson, M., Shackleton, R., Howe, S. and Whiteley, P. (2000) Employers Skill Survey: Case Study Of The Hospitality Sector, Department for Education and Employment, Nottingham.

Schmenner, R.W. (1995) Service Operations Management, Prentice Hall, London.

Schneider, B. \& Bowen, D. E. (1995) Winning the Service Game, Harvard Business School Press, Boston.

Scholarios, D. and Lockyer, C. (1999) "Recruiting and Selecting Professionals: Context, Qualities and Methods", International Journal of Selection and Assessment, Vol. 7 No 3, pp.143-155.

Stalcup, L.D. \& Pearson, T.A. (2001) "A model of the causes of management turnover in hotels", Journal of Hospitality and Tourism Research, Vol 25 No 1, pp.17-30.

Waryszak, R.Z. \& Bauer, T.G. (1993) "Front-office staff selection techniques", International Journal of Contemporary Hospitality Management, Vol 5 No 4, pp. 25-28.

Wood, R.C. (1997) "Personnel management, labour turnover and the role of trade unions", in Wood, R.C. (Ed.), Working in Hotels and Catering, International Thompson Business Press, Oxford. 
Table I

Profile of survey respondents

No.

Ownership

of employees

structure

\begin{tabular}{|c|c|c|c|c|c|}
\hline & $\begin{array}{r}\text { Total } \\
\text { sample }\end{array}$ & $10-25$ & Over 25 & Independent & Chain \\
\hline Number of respondents & 81 & 28 & 53 & 39 & 42 \\
\hline \multicolumn{6}{|l|}{ Type of establishment } \\
\hline Independent & $48 \%$ & $25 \%$ & $23 \%$ & -- & -- \\
\hline Chain/Member of group & $52 \%$ & $10 \%$ & $42 \%$ & -- & -- \\
\hline \multicolumn{6}{|l|}{ Location } \\
\hline City & $16 \%$ & $4 \%$ & $23 \%$ & $5 \%$ & $32 \%$ \\
\hline Suburban & $32 \%$ & $11 \%$ & $44 \%$ & $60 \%$ & $35 \%$ \\
\hline Rural & $52 \%$ & $86 \%$ & $34 \%$ & $35 \%$ & $33 \%$ \\
\hline \multicolumn{6}{|l|}{ Recruitment activity } \\
\hline Replacement only & $77 \%$ & $64 \%$ & $83 \%$ & $78 \%$ & $76 \%$ \\
\hline New posts in same area & $16 \%$ & $14 \%$ & $17 \%$ & $22 \%$ & $12 \%$ \\
\hline New posts in different area & $18 \%$ & $4 \%$ & $10 \%$ & $3 \%$ & $12 \%$ \\
\hline \multicolumn{6}{|l|}{ Numbers hired per year ${ }^{\text {a }}$} \\
\hline Full-time & 17 & 6 & 22 & 14 & 20 \\
\hline Part-time & 14 & 6 & 17 & 12 & 15 \\
\hline Temporary & 27 & 7 & 37 & 10 & 39 \\
\hline \multicolumn{6}{|l|}{ Employee proportions } \\
\hline Full-time & $58 \%$ & $62 \%$ & $56 \%$ & $53 \%$ & $63 \%$ \\
\hline Part-time & $27 \%$ & $30 \%$ & $25 \%$ & $36 \%$ & $18 \%$ \\
\hline Temporary & $22 \%$ & $14 \%$ & $25 \%$ & $14 \%$ & $29 \%$ \\
\hline Unsolicited applications/month (mean) & 14 & 6 & 17 & 5 & 20 \\
\hline No. applications for vacancy (mean) & 20 & 17 & 21 & 11 & 25 \\
\hline \multicolumn{6}{|l|}{ Respondents affected by: } \\
\hline Shortage of suitable applicants & $85 \%$ & $79 \%$ & $89 \%$ & $77 \%$ & $93 \%$ \\
\hline Increased no. of qualified applicants & $30 \%$ & $11 \%$ & $40 \%$ & $26 \%$ & $33 \%$ \\
\hline Increased staff costs & $75 \%$ & $64 \%$ & $81 \%$ & $64 \%$ & $86 \%$ \\
\hline High labour turnover & $59 \%$ & $54 \%$ & $62 \%$ & $54 \%$ & $64 \%$ \\
\hline Equal Opportunity legislation & $31 \%$ & $21 \%$ & $36 \%$ & $33 \%$ & $29 \%$ \\
\hline Health and Safety legislation & $64 \%$ & $64 \%$ & $66 \%$ & $64 \%$ & $67 \%$ \\
\hline European Labour legislation & $31 \%$ & $21 \%$ & $36 \%$ & $23 \%$ & $38 \%$ \\
\hline Price competition & $53 \%$ & $57 \%$ & $51 \%$ & $56 \%$ & $50 \%$ \\
\hline \multicolumn{6}{|l|}{ Staff member responsible for selection } \\
\hline Manager/proprietor & $38 \%$ & $75 \%$ & $19 \%$ & $62 \%$ & $38 \%$ \\
\hline HR staff or department & $30 \%$ & $7 \%$ & $41 \%$ & $3 \%$ & $55 \%$ \\
\hline Split: manager \& heads of departments & $32 \%$ & $18 \%$ & $40 \%$ & $36 \%$ & $29 \%$ \\
\hline Selector tenure with hotel (mean years) & 7 & 8 & 6 & 10 & 4 \\
\hline \multicolumn{6}{|l|}{ Selector personnel experience } \\
\hline Work-based experience & $77 \%$ & $69 \%$ & $81 \%$ & $68 \%$ & $85 \%$ \\
\hline Work-based short courses & $55 \%$ & $42 \%$ & $62 \%$ & $38 \%$ & $71 \%$ \\
\hline Qualifications-based (eg degree) & $35 \%$ & $23 \%$ & $40 \%$ & $11 \%$ & $56 \%$ \\
\hline
\end{tabular}

Note. ${ }^{\text {a }}$ Part-time refers to variable hours but permanent contract; temporary refers to seasonal, non-contractual employment 


\section{Table II}

Recruitment methods used

\begin{tabular}{|c|c|c|c|}
\hline Number \& type of recruitment methods & $\begin{array}{c}\text { Total } \\
\text { sample } \\
(\mathrm{n}=81)\end{array}$ & $\begin{array}{c}10-25 \\
\text { employees } \\
(\mathrm{n}=28)\end{array}$ & $\begin{array}{c}\text { Over } 25 \\
\text { employees } \\
(n=53)\end{array}$ \\
\hline Mean number of methods used ${ }^{a}$ & $\begin{array}{c}3.87 \\
(1.98)\end{array}$ & $\begin{array}{c}3.67 \\
(2.18)\end{array}$ & $\begin{array}{c}3.96 \\
(1.89)\end{array}$ \\
\hline Referrals from existing staff & $75 \%$ & $75 \%$ & $75 \%$ \\
\hline Government agencies & $71 \%$ & $50 \%$ & $81 \%$ \\
\hline Advertising in local press & $68 \%$ & $63 \%$ & $71 \%$ \\
\hline Unsolicited correspondence & $57 \%$ & $54 \%$ & $58 \%$ \\
\hline Educational institutions & $42 \%$ & $38 \%$ & $44 \%$ \\
\hline Past employees & $40 \%$ & $46 \%$ & $37 \%$ \\
\hline Advertising in national press & $15 \%$ & $17 \%$ & $14 \%$ \\
\hline Recruitment agencies & $5 \%$ & $8 \%$ & $4 \%$ \\
\hline
\end{tabular}

Note. Percentages are of total sample

${ }^{a}$ Standard deviations in parentheses 


\section{Table III}

Frequency of use and value attached to selection methods

\begin{tabular}{|c|c|c|c|c|c|c|c|c|c|}
\hline & \multicolumn{3}{|c|}{$\begin{array}{c}\text { Total sample } \\
(\mathrm{n}=54)\end{array}$} & \multicolumn{3}{|c|}{$\begin{array}{c}\text { 10-25 employees } \\
(\mathrm{n}=13)\end{array}$} & \multicolumn{3}{|c|}{$\begin{array}{c}\text { Over } 25 \text { employees } \\
(\mathrm{n}=41)\end{array}$} \\
\hline & $\mathrm{F}^{\mathrm{a}}$ & $\mathrm{V}^{\mathrm{b}}$ & $\mathrm{V}-\mathrm{F}$ & $\bar{F}$ & $\overline{\mathrm{V}}$ & $\mathrm{V}-\mathrm{F}$ & $\bar{F}$ & $\overline{\mathrm{V}}$ & $\mathrm{V}-\mathrm{F}$ \\
\hline One-to-one interview & 4.73 & 4.7 & .05 & 4.42 & 4.82 & .4 & 4. & 4.77 & -.06 \\
\hline Appli & 48 & 4.19 & -.29 & 3.89 & 3.60 & -29 & 4.61 & 35 & -.26 \\
\hline References & 4.26 & 4.35 & .09 & 3.83 & 3.91 & .08 & 4.39 & 4.49 & .10 \\
\hline Letter of application & 3.35 & 3.41 & .06 & 3.09 & 3.60 & .51 & 3.41 & 3.36 & -.05 \\
\hline Curriculum Vitae & 3.35 & 3.88 & .53 & 2.55 & 3.36 & .81 & 3.56 & 4.03 & .47 \\
\hline Person & 3.00 & 3.90 & .90 & 3.50 & 4.36 & .86 & 2.85 & 3.76 & .91 \\
\hline Telep & 2.69 & 3.15 & .46 & 3.00 & 3.09 & .09 & 2.60 & 3.17 & .57 \\
\hline Inter & 3.02 & 3.72 & .70 & 2.50 & 2.70 & .20 & 3.15 & 4.03 & .88 \\
\hline Scho & 2.24 & 2.68 & .44 & 2.00 & 2.36 & .36 & 2.32 & 2.79 & .47 \\
\hline Knov & 2.69 & 3.67 & .98 & 2.73 & 3.70 & .97 & 2.68 & 3.66 & .98 \\
\hline Recrui & 1.71 & 2.24 & .53 & 1.82 & 1.82 & 0 & 1.68 & 2.39 & .71 \\
\hline Job/wo & 1.60 & 2.88 & 1.28 & 1.58 & 2.50 & .92 & 1.61 & 3.04 & 1.43 \\
\hline Test & 1.57 & 2.59 & 1.02 & 1.55 & 2.20 & .65 & 1.57 & 2.79 & 1.22 \\
\hline Test of specif & 1.53 & 2.65 & 1.12 & 1.70 & 2.10 & .40 & 1.48 & 3.00 & 1.52 \\
\hline Test & 1.78 & 2.70 & .92 & 1.82 & 2.00 & .18 & 1.76 & 3.05 & 1.29 \\
\hline Self as & 1.79 & 3.58 & 1.00 & 2.00 & 2.44 & .44 & 1.74 & 2.95 & 1.21 \\
\hline Interest inventory & 1.43 & 2.13 & .70 & 1.70 & 1.56 & -.14 & 1.33 & 2.47 & 1.17 \\
\hline Personality questionna & 1.61 & 2.60 & .99 & 1.44 & 1.67 & .23 & 1.66 & 3.12 & 1.46 \\
\hline Group e & 1.29 & 2.20 & .91 & 1.00 & 1.63 & .63 & 1.36 & 2.47 & 1.11 \\
\hline Peer assessment & 1.68 & 2.42 & .74 & 1.50 & 1.88 & .38 & 1.73 & 2.67 & .94 \\
\hline Assessment centres & 1.15 & 1.90 & .75 & 1.00 & 1.38 & .38 & 1.19 & 2.23 & 1.04 \\
\hline
\end{tabular}

Note.

${ }^{\mathrm{a}} \mathrm{F}$ : Frequency of use ( $1=$ never used, $5=$ always used)

${ }^{\mathrm{b}} \mathrm{V}$ : Value of method for assessing qualities (1=not at all useful, 5=extremely useful) 